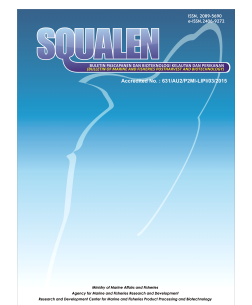

www.bbp4b.litbang.kkp.go.id/squalen-bulletin

Squalen Bulletin of Marine and Fisheries Postharvest and Biotechnology

ISSN: 2089-5690

e-ISSN: 2406-9272

\title{
EVALUATION OF NON-SACCHAROMYCES CEREVISIAE STRAINS ISOLATED FROM SEA WATER AGAINST INHIBITORY COMPOUNDS FOR ETHANOL PRODUCTION
}

\author{
Ahmad Thontowi ${ }^{\star}$, Filemon Jalu Nusantara Putra, and Yopi \\ Laboratory of Biocatalyst and Fermentation, Research Center for Biotechnology, LIPI, \\ Jalan Raya Bogor Km. 46, Cibinong, 16911, Bogor \\ Article history: \\ Received: 27 April 2017; Revised: 23 June 2017; Accepted: 10 July 2017
}

\begin{abstract}
An important parameter in industrial bioethanol fermentation is the resistance of yeast to osmotic pressure and inhibitor compounds. Aureobasidium pullulans LBF-3-0074 and Schwanniomyces etchellsii LBF-3-0034 are reported capable to produce ethanol. LBF-3-0034 and LBF-3-0074 are yeast strains isolated from Bali and Lombok sea water. This study aimed to evaluate characteristics of both LBF-3-0034 and LBF-3-0074 strains under the effects of glucose and inhibitor compounds. Both strains were allowed to consume glucose up to $120 \mathrm{mM}$. Then, these strains were grown with the present of several inhibitors, i.e. 5-hydroxymethyl-2-furaldehyde (5-HMF), furfural, acetic acid, formic acid, and levulinic acid. Results showed that the two yeast strains studied could grow and ferment the sugars under both osmotic and inhibitor stress conditions. As conclusion, Schwanniomyces etchellsii LBF-3-0034 and Aureobasidium pullulans LBF-3-0074 are potential for direct fermentation of lignocellulosic hydrolysate to ethanol.
\end{abstract}

Keywords: bioethanol, inhibitors, osmotic, marine yeast

\section{Introduction}

Identifying new energy resources become an important alternative when the depletion of fossil fuels stock and environmental occurs. International trend currently focused on finding renewable energy resources as an alternative (Chandel et al., 2007; Shweta, Pandeyb, \& Dwivedia, 2016). Bioethanol is important liquid biofuels as an alternative energy. Production of bioethanol has increased in the last decade (Pensupa, Jin, Kokolski, Archer, \& Du, 2013). The bioethanol was produced from wheat (3.9 million tonnes), maize (4.1 million tonnes), sugar beet (12.1 million tonnes), barley ( 0.4 million tonnes) and rye (0.4 million tonnes) (Scarlat, Dallemand, Ferrario, \& Nita, 2015).

In general, fresh water and terrestrial yeast strains were used for bioethanol production. Corn cob could be used as a substrate for bioethanol production which consuming 2.7-5.8 gallons of fresh water per gallon of product (Wu \& Chiu, 2011). Thus, using seawater that contains a spectrum of minerals and essential nutrients required for fermentation medium (Lin, Luque, Clark, Webb, \& Du, 2011) is a promising alternative for bioethanol production. Moreover, since most of Indonesian area is marine, the use of seawater as a medium for bioethanol production will potentially improve the overall economics of the process by both reducing the fresh water intake and producing fresh water through distillation in the biorefinery (Zaky, Tucker, Daw, \& Du, 2014).

Torula sp. and mycoderma are the first marine yeasts isolated from the Atlantic Ocean by Bernhard Fischer in 1894 (Kutty \& Philip, 2008). Later, few marine yeast strains were reported to be able to produce ethanol including Saccharomyces cerevisiae C19 isolated from Tokyo Bay (Obara, Ishida, HamadaSato, \& Urano, 2012) and mangrove sediment (Saravanakumar, Senthilraja, \& Kathiresan, 2013). Several papers reported that non-S. cerevisiae marine yeast strains like Candida sp., Debaromyces hansenii,

${ }^{*}$ Corresponding author.

E-mail: athontowi707@gmail.com 
Geotrichum sp., Pichia fermentans, Pichia salicaria, Pichia capsulate, Pichia salicaria, R. minuta, and $Y$. lipolytica are also bioethanol producers (Kathiresan, Saravanakumar, \& Senthilraja, 2011; Senthilraja, Kathiresan, \& Saravanakumar, 2011; Khambhaty et al., 2013).

It has been well established that bioethanol could be produced by yeast. Yeast strains assimilate glucose and other monosaccharides derived from enzymatic hydrolysis of starch (Tanimura et al., 2015). The global trend of renewable energy uses various materials, such as those derived from lignocellulosic biomass including herbaceous and woody plants, agricultural and forestry residues, municipal solid waste and industrial waste streams (Van Wyk, 2001; Fujita et al., 2002; Tesfaw \& Assefa 2014). Biomass from marine biodiversity is abundant in Indonesia. Marine biomass like seaweed, sawdust, and microalgae are also potential as alternative sources to generate bioethanol (Khambhaty et al., 2013; Martosuyono, Hakim, \& Fawzya, 2015; Nguyen \& Hanh, 2012; Saravanakumar, Senthilraja, \& Kathiresan, 2013). These feedstocks have its own charm as they do not compete with food supply (Sun \& Cheng, 2002).

Lignocellulosic waste from plant contains up to $70 \%$ of carbohydrates (cellulose and hemicellulose). Cellulose and hemicellulose are important substrates for second generation of bioethanol development. However, due to the complexity of lignocellulosic structure, it is necessary to provide pretreatment to release the sugar. The sugar will be used for fermentation process to produce ethanol. Pretreatment processing can be carried out in many different ways including mechanical, steam explosion, ammonia fiber explosion, acid or alkaline pretreatment and biological pretreatment (Chandel et al., 2007).

Fermentation processes using lignocellulosic waste has limitation since formation of sugar monomer is accompanied by inhibitory compounds production (Barber, Hansson, \& Pamment, 2000; Kathiresan, Saravanakumar, \& Senthilraja, 2011; Palmqvist, Grage, Meinander, \& Hahn-Hagerdal, 1999; Palmqvist \& HahnHagerdal, 2000). The inhibitory compounds fall into specific groups such as weak acids, furan derivatives and phenolic compounds (Barber, Hansson, \& Pamment, 2000). The types and concentrations of toxic compounds generated in lignocellulosic hydrolysates depend on both raw material and operational condition employed for hydrolysis (Palmqvist et al., 1999; Palmqvist \& Hahn-Hagerdal, 2000). Toxic compounds stress the fermentative organisms to a point beyond which the efficient utilization of sugars is possible, ultimately leading to reduce the product formation (Palmqvist \& HahnHagerdal, 2000; Modig, Lidén, \& Taherzadeh, 2002).

Aureobasidium pullulans LBF-3-0074 and Schwanniomyces etchellsii LBF-3-0034 are yeast isolated from Bali and Lombok sea water area. These strains have been known as ethanol producer. The objective of this study is to evaluate the effect of glucose concentration and the inhibitor compounds on these strains.

\section{Materials and Methods}

\subsection{Strains of Yeast}

Two strains of yeast, $A$. pullulans LBF-3-0074 and S. etchellsii LBF-3-0034 isolated from Bali and Lombok bay sea waters respectively, were evaluated in this study. Both strains were culture collection of Laboratorium of Biocatalyst and Fermentation, Research Center for Biotechnology, Indonesian Institute of Sciences (LIPI). Routine subculture and maintenance, were conducted by growing the yeast on yeast malt $(\mathrm{YM})$ agar or broth at $30^{\circ} \mathrm{C}$.

\subsection{Yeast Fermentation in Various Glucose Concentrations}

Isolates were cultured in $1000 \mathrm{~mL}$ of Yeast Peptone Dextrose (YPD), a media containing $10 \mathrm{~g} / \mathrm{L}$ yeast extract, $20 \mathrm{~g} / \mathrm{L}$ peptone and $20 \mathrm{~g} / \mathrm{L}$ glucose. Fermentation was conducted overnight at $30^{\circ} \mathrm{C}$ with shaking $1400 \mathrm{rpm}$. Both ethanol producing strains were grown in YPD medium containing various glucose concentrations $(0,10,30,60,100$, and $120 \mathrm{mM})$. Fermentation was performed in the deep well containing $1 \mathrm{~mL}$ medium. The cultures were incubated at $30^{\circ} \mathrm{C}$ with shaking $1400 \mathrm{rpm}$ for $24 \mathrm{~h}$ in an incubatorshaker (Bio Shaker MBR-022UP, Titec, Japan). All experiments were performed in triplicates. The cell growth was then analyzed using spectrophotometer at $600 \mathrm{~nm}$. The fermentation products were then analyzed based on glucose consumption and ethanol production parameters using High-performance liquid chromatography (HPLC) (Saczk, Okumura, de Oliveira, Boldrin, \& Ramos, 2005; Yarita et al., 2002).

\subsection{Yeast Fermentation in Various Inhibitor Compounds}

Two ethanol producing yeasts were grown in YPD medium containing $50 \mathrm{~g} / \mathrm{L}$ of glucose and $50 \mathrm{mM}$ of some inhibitor compounds i.e 5-hydroxymethyl-2furaldehyde (5-HMF), furfural, acetic acid, formic acid and levulinic acid. Fermentation was performed in the 
deep well for $1 \mathrm{~mL}$ of YPD medium. The cultures were incubated at $30^{\circ} \mathrm{C}$ with shaking $1400 \mathrm{rpm}$ for $24 \mathrm{~h}$. As a fermentation control, the strains were grown in YPD medium containing $50 \mathrm{~g} / \mathrm{L}$ of glucose without inhibitor compound added. All experiments were performed in triplicates. The cell growth was analyzed using spectrophotometer at $600 \mathrm{~nm}$. The obtained fermentation products were analyzed using HPLC (Yarita et al., 2002; Saczk et al., 2005).

\subsection{Yeast Fermentation in Medium Containing Inhibitor Compounds}

Yeast Nitrogen Base (YNB) medium containing $50 \mathrm{~g} / \mathrm{L}$ glucose, $50 \mathrm{~g} / \mathrm{L}$ xylose, $6.7 \mathrm{~g} / \mathrm{L}$ yeast nitrogen base (without amino acids) was used as an inhibitorfree medium. YNB medium supplemented with $60 \mathrm{mM}$ acetic acids, $30 \mathrm{mM}$ formic acid, $60 \mathrm{mM}$ furfural, $10 \mathrm{mM}$ 5-HMF, 5mM levulinic acid was used as an inhibitory medium (YS medium) (Purwadi, Brandberg, \& Taherzadeh, 2007). YS medium was diluted with YNB medium at 0.2 -fold (0.2YS medium). YNB medium was used as control of fermentation. The cultivations batch were carried out in $100 \mathrm{~mL}$ erlenmeyer flask at $30^{\circ} \mathrm{C}$ with shaking $150 \mathrm{rpm}$ in orbital shaker incubator for $30 \mathrm{~h}$. $1.2 \mathrm{~mL}$ of pre-culture was inoculated in 12 $\mathrm{mL}$ of fermentation medium (to give $10 \%$ inoculation size). Sample was taken every $3 \mathrm{~h}$ during the fermentation process. The sample was centrifuged at $6000 \mathrm{~g}$ for $5 \mathrm{~min}$, and then $350 \mu \mathrm{L}$ of supernatant was transferred into vials for HPLC analysis. The growth of the cell was monitored with $\mathrm{OD}_{600}$ measurement using UV mini-1240 (UV-VIS Spectrophotometer, Shimadzu, Tokyo).

\subsection{HPLC Analysis}

HPLC was used to monitor the products obtained after fermentation process by both $S$. etchellsii LBF3-0034 and A. pullulans LBF-3-0074. The fermentation products of yeasts (glucose, xylose, ethanol and lactic acid) were measured by using an HPLC system (LC20AD pump, RI detector RID-10A, Shimadzu, Kyoto, Japan) with an Aminex HPX-87H column (Bio-Rad Laboratories, Hercules, CA, USA) after filtration through a Mini-UniPrepTMsyringeless filter device (GE Healthcare Companies). The HPLC system was operated at $65^{\circ} \mathrm{C}$ using $0.6 \mathrm{~mL} / \mathrm{min}$ of $5 \mathrm{mM} \mathrm{H}_{2} \mathrm{SO}_{4}$ as the mobile phase. The ethanol yield calculation was based on the following equation (Nutawan et al., 2010):

$$
\text { Ethanol yield }=\frac{(\text { Measured ethanol in sample }(\mathrm{g}))}{\text { (Theoretical ethanol }(\mathrm{g}))}
$$

Theoretical $=0.5 \mathrm{x}$ amount of initial sugar content $(\mathrm{g})$ ethanol $(\mathrm{g})$ in fermentation solution

\section{Results and Discussion}

\subsection{The characteristic of Yeasts in Various Glucose Concentrations}

A. pullulans LBF-3-0074 and S. etchellsii LBF-30034 were grown in various glucose concentrations (0-120 mM). The growth of both strains showed different results. The LBF-3-0034 strain had optimal cell growth at a concentration of $10 \mathrm{mM}$ glucose. The use of glucose at concentration more than $10 \mathrm{mM}$ decreased the cell growth (Figure 1A). On the other hand, the LBF-3-0074 strain had optimal cell growth in $100 \mathrm{mM}$ glucose, yet the cell growth decreased at the concentrations above it.

Based on the results, it appeared that both strains have maximum tolerance concentration of glucose for the cell growth. High concentration of glucose in the fermentation medium could be an osmotic stress for yeast. A high osmotic potential is caused by the pressure of sugar in the medium that may increase the toxicity caused by ethanol (Estruch, 2000; Gibson et al., 2007; da Silva et al., 2013). The high sugar concentration can delay the beginning of the fermentation (lag phase) and establish osmotic adverse conditions for the yeast (Silva et al., 2013). Cell growth of S. etchellsii LBF-3-0034 and $A$. pullulans LBF-3-0074 correlates with their ability to consume glucose as a carbon source. S. etchellsii LBF-3-0034 consumed glucose less than A. pullulans LBF-3-0074 strain (Figure 1 B).

A. pullulans LBF-3-0074 strain performed $38 \%$ conversion of $100 \mathrm{mM}$ glucose into ethanol (Figure 1D). The yeast cell may experience osmotic stress then loss of water in cytoplasmic. The yeast will activate several mechanisms to protect cell from dehydration (Estruch, 2000). The adaptive of yeast cell from various stresses during alcohol fermentation is an important key to the process. For that reason the selection of yeast cells as a fermentation agent becomes the determinant of ethanol production efficiency (da Silva, Batistote, \& Cereda, 2013).

The yeast glycolytic pathway showed that glucose could be converted into ethanol. In this study, $A$. pullulans LBF-3-0074 strain is capable of producing ethanol higher than S. etchellsii LBF-3-0034 strain. At concentration of 100 and $120 \mathrm{mM}$ glucose, $A$. pullulans LBF-3-0074 strain produced ethanol of 14 and $22.5 \mathrm{~g} / \mathrm{L}$, respectively (Figure 1.C). At the same glucose concentration, S. etchellsii LBF-3-0034 strain only produced ethanol of 5 and $4.7 \mathrm{~g} / \mathrm{L}$. This shows that at concentration up to $120 \mathrm{mM}$ of glucose, both strains still able to produce ethanol which means that 
(A)

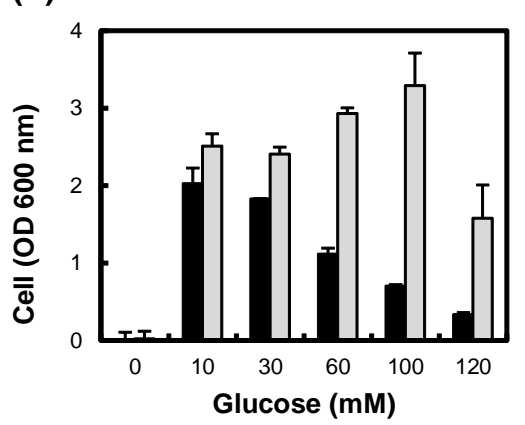

(C)

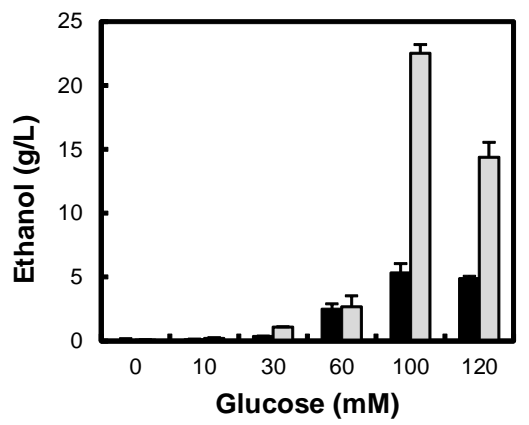

(B)

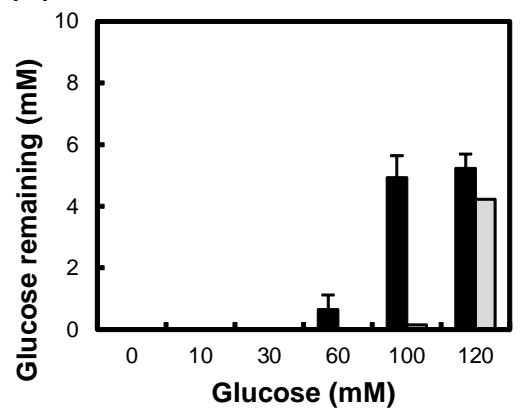

(D)

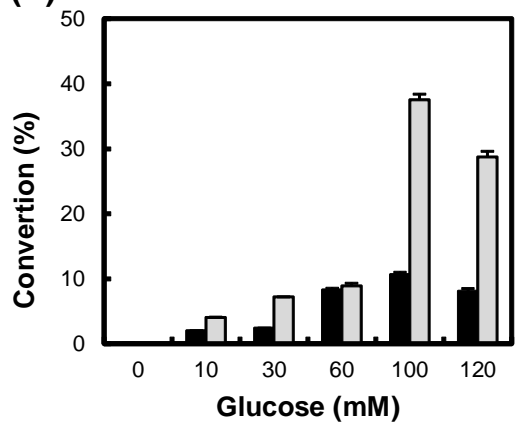

Figure 1. The characteristic of S. etchellsii LBF-3-0034 and A. pullulans LBF-3-0074 for glucose effects to (A) the cell growth, (B) glucose consumption, (C) ethanol production, and (D) conversion of ethanol. The fermentations were conducted for 24 hours at $30^{\circ} \mathrm{C}$ and $1400 \mathrm{rpm}$ in deep well scale. S. etchellsii LBF-3-0034 strain, $\square$ A. pullulans LBF-3-0074 strain.

both yeast strains are able to resist the osmotic pressure. Based on these results, at a concentration of $100 \mathrm{mM}$ of glucose, A. pullulans LBF-3-0074 strain produces higher conversion rates than S. etchellsii LBF-3-0034 strain (Liang et al., 2013).

\subsection{The Characteristic of Yeasts in Various Inhibitors Compounds}

S. etchellsii LBF-3-0034 and A. pullulans LBF-30074 strains were grown in various inhibitors compounds i.e. 5-HMF, furfural, acetic acid, formic acid and levulinic acid to determine the tolerance level to the inhibitors tested. These inhibitor have been shown to have toxic effects on cells which causing damage by inhibiting enzymes produced by microorganisms (Cantarella et al., 2004; Allen et al., 2010) or by impeding enzymes responsible for fermentation which then affecting their membrane integrity (Mills et al., 2009; Queìmeìneur et al., 2012). However, the result showed that both $A$. pullulans LBF3-0074 and S. etchellsii LBF-3-0034 strains were still optimally grown in the 5-HMF-added medium (Figure $2 A)$. Additionally, the $A$. pullulans LBF-3-0074 strain showed higher cell growth compare to S. etchellsii LBF-3-0034 strain.
The ability of the two strains to grow in a medium containing inhibitor compounds is accompanied by the production of ethanol. Both of the yeast strains studied able to produce highest ethanol yield when they were grown in 5-HMF-containing medium compare to when they were grown in other inhibitorcontaining medium. This suggests that both studied strains are resistant to yeast inhibitor compound and still have the ability to produce ethanol under inhibitor stressed condition (Jönsson \& Martín, 2016). The tolerant ethanologenic yeast strains were found to be able to convert furfural and 5-HMF, representative inhibitors for biomass pretreatment, into less toxic compounds furanmethanol (FM) and furan-2,5dimethanol (FDM; 2,5-bis-hydroxyme- thylfuran) while producing normal yields of ethanol (Liu et al., 2004; Talebnia \& Taherzadeh, 2006; Martín et al., 2007; Liu et al., 2008).

\subsection{The Strains Survivals Under the Presence of Inhibitory Compounds at Different Concentrations}

Figure $3 \mathrm{~A}$ and $3 \mathrm{~B}$ showed that $A$. pullulans LBF-30074 and S. etchellsii LBF-3-0034 strains were well grown in YNB medium. However, S. etchellsii LBF-3- 

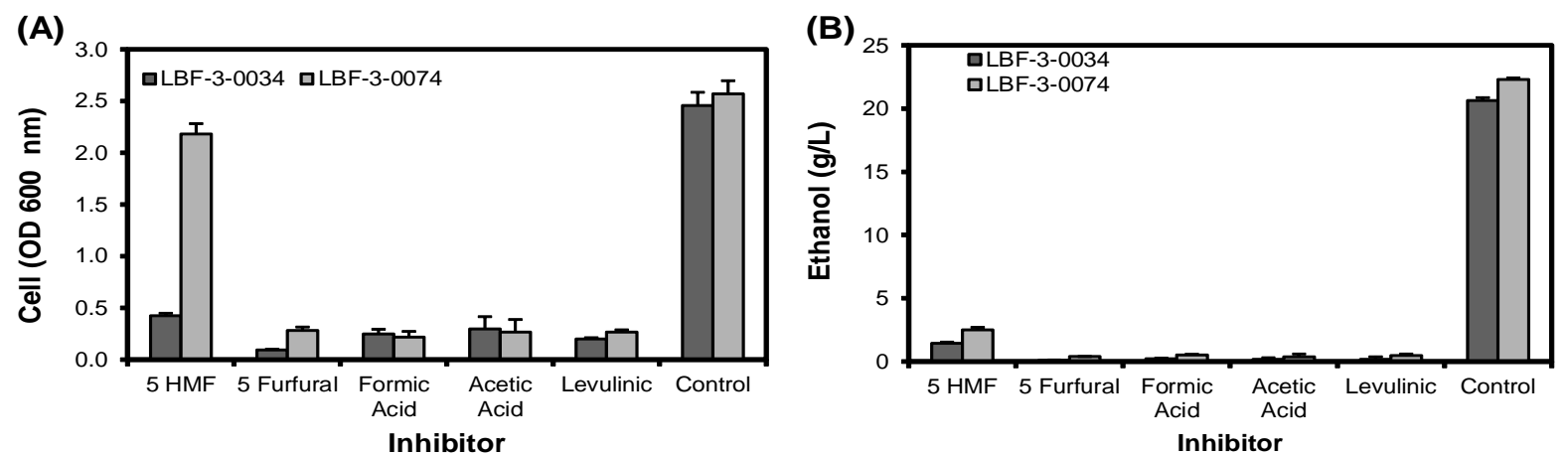

Figure 2. The characteristic of S. etchellsii LBF-3-0034 and A. pullulans LBF-3-0074 for inhibitors effects to (A) the cell growth and (B) ethanol production. The fermentation was conducted for $24 \mathrm{~h}$ at $30^{\circ} \mathrm{C}$ and 1400 rpm in deep well scale.

(A)

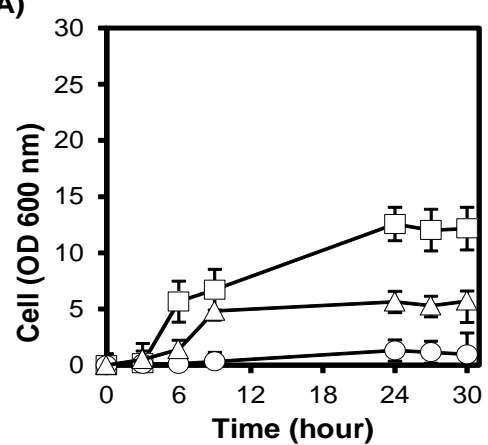

(C)

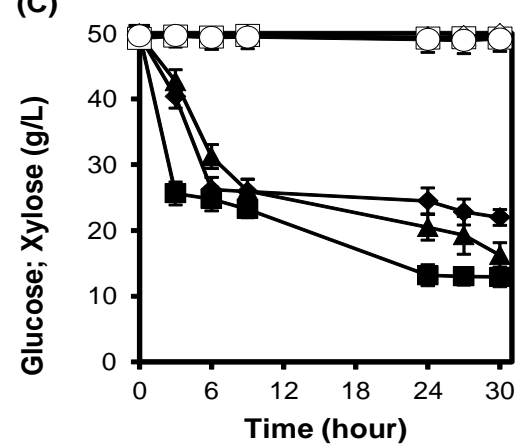

(E)

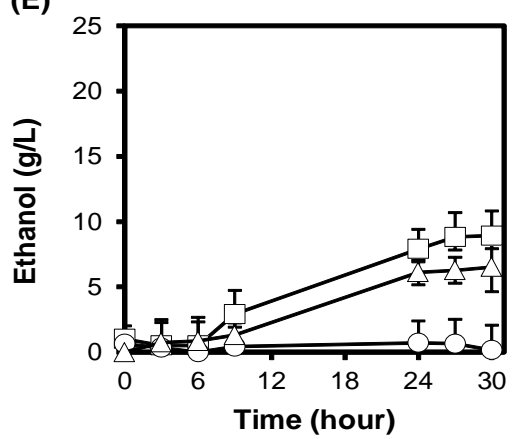

(B)

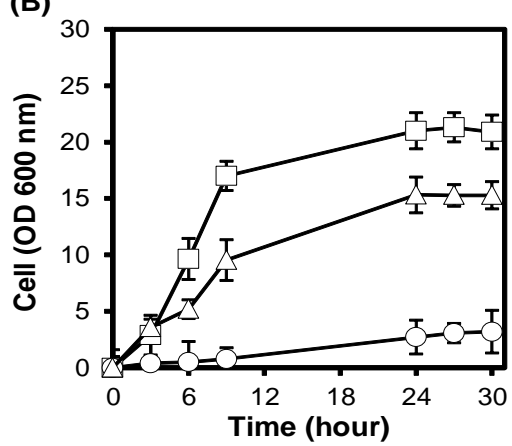

(D)

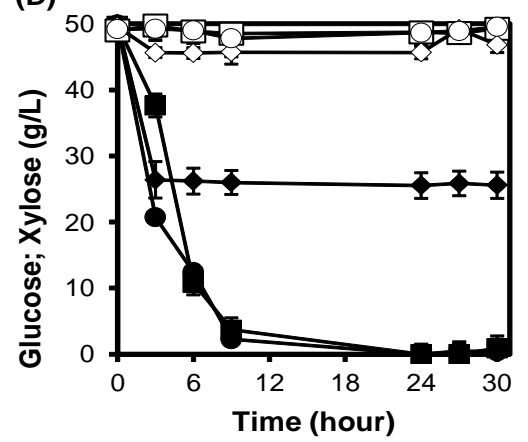

(F)

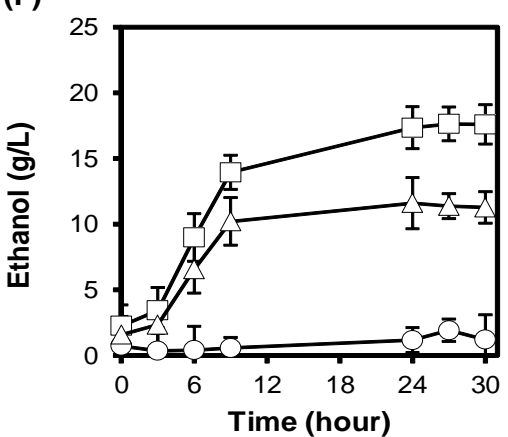

Figure 3. Effect of medium on cell growth, sugars consumption, and ethanol production in S. etchellsii LBF3-0034 (A, C, E) and A. pullulans LBF-3-0074 (B, D, F). The cultures were performed in $12 \mathrm{~mL}$ of $\mathrm{YS}$ medium (circle), $0.2 \mathrm{YS}$ medium (triangle), and YNB medium (square) at $30^{\circ} \mathrm{C}, 150 \mathrm{rpm}$ for $30 \mathrm{~h}$ incubation. Sugars consumption as glucose (black symbols) and xylose (open symbols). The culture was performed independently in triplicate. 

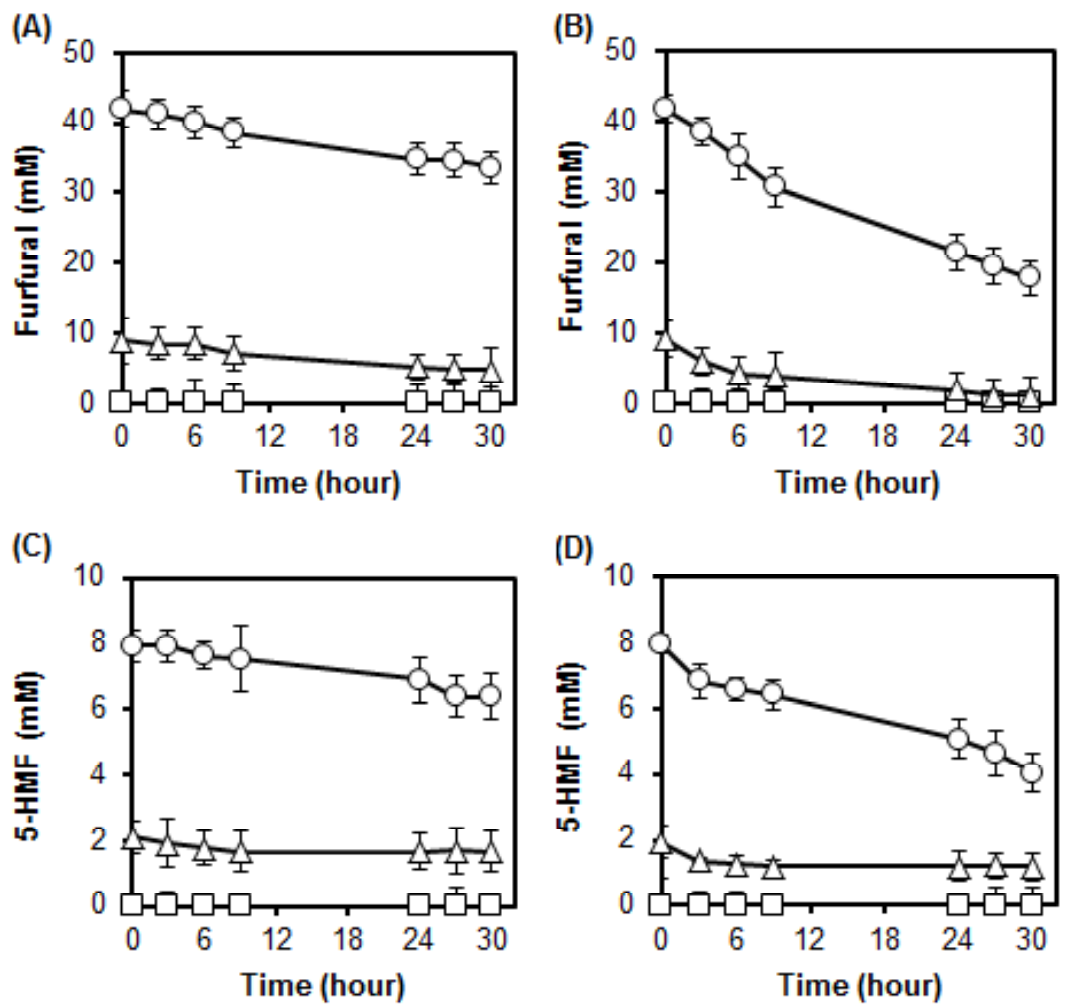

Figure 4. Detoxification of (A) furfural and (C) 5-HMF by S. etchellsii LBF-3-0034 strain and (B) furfural and (D) 5-HMF by A. pullulans LBF-3-0074 strain. The cultures were performed in $12 \mathrm{~mL}$ of YS medium (circle), $0.2 \mathrm{YS}$ medium (triangle), and YNB medium (square) at $30^{\circ} \mathrm{C}, 150 \mathrm{rpm}$ for $30 \mathrm{~h}$ incubation. The culture was performed independently in triplicate.

0034 strain did not grow in YS medium, while $A$. pullulans LBF-3-0074 strain grew with low cell number. The cell growth was stopped as the cells deceased. The growth of both strains was inhibited as the concentration of the inhibitory compounds increased. The glucose consumption was delayed with increasing concentration of the inhibitory compounds (Figure 1C and 1D). Furthermore, the rate of glucose consumption was varied depending on the inhibitory compounds concentration in the medium. S. etchellsii LBF-3-0034 strain consumed glucose optimally up to $24 \mathrm{~h}$ after fermentation on all mediums. Meanwhile, $A$. pullulans LBF-3-0074 strain consumed glucose optimally after 9h fermentation in YNB and 0.2YS media with $2 \mathrm{~g} / \mathrm{L}$ of glucose remaining. In both media of YNB and 0.2 YS, the strains had readily consumed the glucose when the fermentation was started. The glucose was rapidly used just after $6 \mathrm{~h}$ and completely consumed at $24 \mathrm{~h}$. The S. etchellsii LBF-3-0034 strain was rapidly used glucose after $3 \mathrm{~h}$ and completely consumed the glucose at $24 \mathrm{~h}$. This suggests that $A$. pullulans LBF3-0074 strain has higher glucose assimilation capability than S. etchellsii LBF-3-0034 strain. In all medium tested, both strains do not utilize xylose as carbon source, as the xylose concentration remain
$50 \mathrm{~g} / \mathrm{L}$ till the end of fermentation (Figure $3 \mathrm{C}$ and $3 \mathrm{D}$ ). This finding confirmed that the strains could not utilize xylose. According to Moysés et al. (2016) and Nitiyon et al. (2016), the present of high concentration of xylose in the medium causes the osmotic stress for yeast strain.

The ethanol production was a growth-dependent as it increased just after the glucose consumption started (Figure 3E and 3F). S. etchellsii LBF-3-0034 strain produced ethanol by $9 \mathrm{~g} / \mathrm{L}$ in YNB medium and by $6 \mathrm{~g} / \mathrm{L}$ in $0.2 \mathrm{YS}$ medium at $27 \mathrm{~h}$ incubation. Meanwhile, A. pullulans LBF-3-0074 strain produced ethanol by $18 \mathrm{~g} / \mathrm{L}$ in YNB medium and by $12 \mathrm{~g} / \mathrm{L}$ in $0.2 Y S$ medium at $27 \mathrm{~h}$ incubation. Moreover, the ethanol production was depending on the effect of inhibitory compounds in the medium (Horváth et al., 2003; Jönsson \& Martín, 2016).

\subsection{Detoxification of Inhibitory Compounds}

Based on the cell growth and ethanol production data (Figure 4), A. pullulans LBF-3-0074 and S. etchellsii LBF-3-0034 strains could survive likely due to their successful detoxification of the inhibitory compounds (furfural and 5-HMF). For both strains, the 
concentration of furfural and 5-HMF decreased during the fermentation based on their concentration. In YS and 0.2YS media, S. etchellsii LBF-3-0034 strain detoxified $20-45 \%$ of furfural (Figure $4 \mathrm{~A}$ ), while $A$. pullulans LBF-3-0074 strain detoxified $57-90 \%$ of furfural (Figure 4B). In the same mediums, S. etchellsii LBF-3-0034 strain detoxified $25-45 \%$ of 5-HMF (Figure 4C), while A. pullulans LBF-3-0074 able to detoxified up to $50 \%$ of 5 -HMF (Figure 4D). This fact suggests that the ability of $A$. pullulans LBF-3-0074 to detoxify furfural and 5-HMF is better than S. etchellsii LBF-30034. Based on their detoxification rate, both isolates were more potent in detoxifying furfural than 5-HMF. Furfural is a major inhibitor in the lignocellulosic biomass. This compound decreases cell growth, cell budding, ethanol production, and enzyme activity (Modig et al., 2002), changes the TCA and glycolytic fluxes (Horváth et al., 2003), induces the reactive oxygen species (ROS) accumulation and causes cellular damages (Allen et al., 2010). Compared to furfural, 5-HMF is less toxic, since it is difficult to penetrate the cell membranes of yeast. 5-HMF inhibits the key enzyme for ethanol production and induced the cell apoptosis (Modig et al., 2002).

The ethanol production was a growth-dependent as it increased just after the glucose consumption started (Figure 3E and 3F). S. etchellsii LBF-3-0034 strain produced ethanol by $9 \mathrm{~g} / \mathrm{L}$ in YNB medium and by $6 \mathrm{~g} / \mathrm{L}$ in $0.2 \mathrm{YS}$ medium at $27-\mathrm{h}$ incubation. $A$. pullulans LBF-3-0074 strain produced ethanol by 18 $\mathrm{g} / \mathrm{L}$ in $\mathrm{YNB}$ medium and by $12 \mathrm{~g} / \mathrm{L}$ in $0.2 \mathrm{YS}$ medium at $27 \mathrm{~h}$ incubation.

\section{Conclusion}

Biochemical characteristics of Aureobasidium pullulans LBF-3-0074 and Schwanniomyces etchellsii LBF-3-0034 yeast strains that were grown under the effects of glucose and inhibitors were evaluated. These strains could grow and produce ethanol in medium containing several concentrations of glucose and inhibitors. Both strains consumed glucose up to 120 $\mathrm{mM}$. They also could grow with the presence of several inhibitors, i.e. 5-HMF, furfural, acetic acid, formic acid, and levulinic acid. Based on the cell growth and ethanol production data, A. pullulans LBF-3-0074 and S. etchellsii LBF-3-0034 were survived due to their successful detoxification of furfural and 5-HMF. As conclusion, both strains are potential to be used for direct fermentation of lignocellulosic hydrolysate to ethanol.

\section{Acknowledgment}

This study was financially supported by the International Joint Program, Science and Technology
Research Partnership for Sustainable Development (SATREPS): "Innovative Bio-Production in Indonesia (iBiol)" from the Japan Science and Technology Agency and the Japan International Cooperation Agency (JST and JICA), and DIPA of Indonesian Institute of Sciences (LIPI) 2016-2017.

\section{References}

Allen, S.A., Clark, W., McCaffery, J.M., Cai, Z., Lanctot, A., Slininger, P.J., Liu, Z.L., \& Gorsich, S.W. (2010). Furfural induces reactive oxygen species accumulation and cellular damage in Saccharomyces cerevisiae. Biotechnology for Biofuels, 3, 2. http://www.biotechnology forbiofuels. com/content/3/1/2 RESEARCH

Barber, A.R., Hansson, H., \& Pamment, N.B. (2000). Acetaldehyde stimulation of the growth of Saccharomyces cerevisiae in the presence of inhibitors found in lignocellulose to ethanol fermentations. Journal of Industrial Microbiology \& Biotechnology, 25, 104-108. 10.1038/sj.jim.7000031

Cantarella, M., Cantarella, L., Gallifuoco, A., Spera, A., \& Alfani, F. (2004). Effect of inhibitors released during steam-explosion treatment of poplar wood on subsequent enzymatic hydrolysis and SSF. Biotechnology Programme, 20, 200-206.

Chandel, A.K., Chan, E.C., Rudravaram, R., Narasu, M.L., Rao, L.V., \& Ravindra, P. (2007). Economics and environmental impact of bioethanol production technologies: an appraisal. Biotechnology Molecular Biology Review, 2,14-32.

da Silva R.O., Batistote, M., \& Cereda, M.P. (2013). Alcoholic fermentation by the wild yeasts under thermal, osmotic and ethanol stress. Brazillian Archives of Biology and Technology, v.56(2), 161-169. http://dx.doi.org/10.1590/S1516-89132013000 200001

Estruch, F. (2000). Stress-controlled transcription factors, stress- induced genes and stress tolerance in budding yeast. Review FEMS Microbiology, 24, 469486.

Fujita, Y., Takahashi, S., Ueda, M., Tanaka, A., Okada, H., Morikawa, Y., Kawaguchi ,T., Arai, M., Fukuda, H., \& Kondo, A. (2002). Direct and efficient production of ethanol from cellulosic material with a strain displaying cellulolytic enzyme. Applied Environmental Microbiology, 68(10), 5135-5141.

Gibson, B.R., Lawrence, S.J., Leclaire, J.P.R, Powell, C.D., \& Smart, K.A. (2007). Yeast responses to stresses associated with industrial brewery handling. FEMS Microbiol Rev, 31, 535-569, DOI: 10.1111/ j.1574-6976.2007.00076.x

Horváth, I.S., Franzén, C.J., Taherzadeh, M.J., Niklasson, C., \& Lidén, G. (2003). Effects of furfural on the respiratory metabolism of Saccharomyces cerevisiae in glucose-limited chemostats. Applied Environmental Microbiology, 69(7), 4076-4086.

Jönsson, L.J, \& Martín, C. (2016). Pretreatment of lignocellulose: Formation of inhibitory by-products 
and strategies for minimizing their effects. Bioresource Technology, 199:103-112.

Kathiresan, K., Saravanakumar, K., \& Senthilraja, P. (2011). Bioethanol production by marine yeasts strain from coastal mangrove sediment. International Multidisciplinary Research Journal, 1,19-24.

Khambhaty, Y., Upadhyay, D., Kriplani, Y., Joshi, N., Mody, K. \& Gandhi, M.R. (2013). Bioethanol from macroalgal biomass: utilization of marine yeast for production of the same. Bioenergy Research, 6, 188-195.

Kutty, S.N., \& Philip, R. (2008). Marine yeasts - a review. Yeast, 25: 465-483.

Liang, W., Xin-Qing, Z., Chuang, X., \& Feng, W. (2013). Impact of osmotic stress and ethanol inhibition in yeast cells on process oscillation associated with continuous very-high-gravity ethanol fermentation. Biotechnology Biofuels, v.6:133. doi: 10.1186/17546834-6-133

Lin, C.S.K., Luque, R., Clark, J.H., Webb, C., \& Du, C. (2011). A seawater-based biorefining strategy for fermentative production and chemical transformations of succinic acid. Energy Environmental Science, 4: 1471-1479.

Liu, Z.L., Moon, J., Andersh, A.J., Slininger, P.J., \& Weber, S. (2008). Multiple gene mediated $\mathrm{NAD}(\mathrm{P}) \mathrm{H}-$ dependent aldehyde reduction is a mechanism of in situ detoxification of furfural and HMF by ethanologenic yeast Saccharomyces cerevisiae. Applied Microbiology Biotechnology, 81, 743-753.

Liu, Z.L., Slininger, P.J., Dien, B.S., Berhow, M.A., Kurtzman, C.P., \& Gorsich, S.W. (2004). Adaptive response of yeasts to furfural and 5hydroxymethylfurfural and new chemical evidence for HMF conversion to 2, 5-bis-hydroxymethylfuran. Journal of Industrial Microbiology and Biotechnology, 31, 345-352.

Martín, C., Marcet, M., Almazán, O., \& Jönsson, L.J. (2007). Adaptation of a recombinant xylose-utilizing Saccharomyces cerevisiae strain to a sugarcane bagasse hydrolysate with high content of fermentation inhibitors. Bioresource Technology, 98, 1767-1773.

Martosuyono, P., Hakim, A. \& Fawzya, Y.N. (2015). Chemical pretreatment and enzymatic saccharification of seaweed solid wastes. Squalen Bulletin of Marine \& Fish. Postharvest \& Biotech, 10(2), 61-71.

Mills, T.Y., Sandoval, N.R., \& Gill, R.T. (2009). Cellulosic hydrolysate toxicity and tolerance mechanisms in Escherichia coli. Biotechnology Biofuel, 2, 26. https:/ /doi.org/10.1186/1754-6834-2-26

Modig, T., Lidén, G., \& Taherzadeh, M.J. (2002). Inhibition effects of furfural on alcohol dehydrogenase, aldehyde dehydrogenase and pyruvate dehydrogenase. Biochemical Journal, 363(P3), 769-776.

Moysés, D.N, Reis, V.C.B., de Almeida, J.R.M, de Moraes, L.M.P., \& Torres, F.A.G. (2016). Xylose Fermentation by Saccharomyces cerevisiae: Challenges and Prospects. International Journal of Molecular Science, 17(3), 207, doi: 10.3390/ijms17030207
Nguyen, T.H.M., \& Hanh, V.V. (2012). Bioethanol production from marine algae biomass: prospect and troubles. Journal of Vietnamese Environt, 3(1), 2529. DOI (PDF): http://dx.doi.org/10.13141/ jve.vol3.no1.pp25-29.g22

Nitiyon, S., Keo-oudone C., Murata, M., Lertwattanasakul, N., Limtong, S., Kosaka, T., \& Yamada, M. (2016). Efficient conversion of xylose to ethanol by stresstolerant Kluyveromyces marxianus BUNL-21, Springerplus, 5, 185. doi:10.1186/s40064-016-18816

Nutawan, Y., P. Phuriphipat, P., Treyawutthiwat \& Eshtiaghi, M.N. (2010). Bioethanol production from rice straw, Energy Research Journal, 1(1), 26-31.

Obara, N., Ishida, M., Hamada-Sato, N., \& Urano, N. (2012). Efficient bioethanol production from scrap paper shredder by a marine Saccharomyces cerevisiae derived C-19. Studies in Science Technology, 1, 127-132.

Palmqvist, E., \& Hahn-Hagerdal, B. (2000). Fermentation of lignocellulosic hydrolysates. I: Inhibition and detoxification. Bioresource Technology, 74, 17-24.

Palmqvist, E., Grage, H., Meinander, N.Q., \& HahnHagerdal, B. (1999). Main and interaction effects of acetic acid, furfural and hydroxybenzoic acid on growth and ethanol productivity of yeasts. Biotechnology Bioengeenering, 63, 46-55. PMID: 10099580.

Pensupa, N., Jin, M., Kokolski, M., Archer, D.B., \& Du, C. (2013). A solid state fungal fermentation-based strategy for the hydrolysis of wheat straw. Bioresource Technology, 149, 261-267. doi:10.1016/j.biortech. 2013.09.061

Purwadi, R., Brandberg, T., \& Taherzadeh, M.J. (2007). A possible industrial solution to ferment lignocellulosic hydrolyzate to ethanol: continuous cultivation with flocculating yeast. International Journal of Molecular Science, 8(9), 920-932.

Queìmeìneur, M., Hamelin, J., Barakat, A., Steyer, J.P., Carrel̀re, H., \& Trably, E. (2012). Inhibition of fermentative hydrogen production by lignocellulosederived compounds in mixed cultures. International Journal of Hydrogen Energy, 37, 3150-3159.

Saczk, A.A., Okumura, L.L., de Oliveira F.M., Boldrin, Z.M.V., \& Ramos, S.N. (2005). Rapid and sensitive method for the determination of acetaldehyde in fuel ethanol by high-performance liquid chromatography with UVVis detection. Analytical and Bioanalytical Chemistry, 381(8),1619-24.

Saravanakumar, K., Senthilraja, P. \& Kathiresan, K. (2013). Bioethanol production by mangrove-derived marine yeast Sacchromyces cerevisiae. Journal of King Saud University-Science, 25, 121-127.

Scarlat, N., Dallemand, J.F., Ferrario, F.M., \& Nita, V. (2015). The role of biomass and bioenergy in a future bioeconomy: Policies and facts. Environmental Development, 15:3-34.

Senthilraja, P., Kathiresan, K. \& Saravanakumar, K. (2011) Comparative analysis of bioethanol production by different strains of immobilized marine yeast. Journal of Yeast Fungal Research, 8, 113-116. 
Shweta, S., Pandeyb, A., \& C.K., Dwivedia. (2016). Bioelectricity production from various feedstocks using pure strain of Bacillus firmus. International Journal Renewable Energy Development, 5(2), 119127.

Sun, Y., \& Cheng, J. (2002). Hydrolysis of lignocellulosic materials for ethanol production: a review. Bioresource Technology, 83, 1-11.

Talebnia, F., \& Taherzadeh, M.J. (2006). In situ detoxification and continuous cultivation of dilute-acid hydrolysate to ethanol by encapsulated Saccharomyces cerevisiae. Journal of Biotechnology, 125, 377-384.

Tanimura, A., Kikukawa, M., Yamaguchi, S., Kishino, S. Ogawa, J., \& Shima, J. (2015). Direct ethano production from starch using a natural isolate, Scheffersomyces shehatae: toward consolidated bioprocessing. Scientific Reports 5: 9593. DOI: 10.1038/srep09593

Tesfaw, A. \& Assefa, F. (2014). Current trends in bioethanol production by Saccharomyces cerevisiae: substrate, inhibitor reduction, growth variables, coculture and immobilization. International Scholarly
Research Notices, ID 532852, 11 pages. doi:10.1155/ 2014/532852

Van Wyk, J.P.H. (2001). Biotechnology and the utilization of biowaste as a resource for bioproduct development. Trends Biotechnology, 19, 172-177. PMID: 11301129

Walker, G.M. (1998). Yeast. Physiology and Biotechnology. London, UK: John Wiley and Sons Publishers.

Wu, M. \& Chiu, Y. (2011). Consumptive Water Use in the Production of Ethanol and Petroleum Gasoline. Transportation Technology R\&D Center, USA. Available at: http://greet.es.anl.gov/publicationconsumptive-water.

Yarita, T., Nakajima, R., Otsuka, S., Ihara, T.A., Takatsu, A., \& Shibukawa, M. (2002). Determination of ethanol in alcoholic beverages by high-performance liquid chromatography-flame ionization detection using pure water as mobile phase. Journal of Chromatography, A, 8, 976(1-2), 387-91.

Zaky, A.S., Tucker, G.A., Daw, Z.Y., \& Du, C. (2014). Marine yeast isolation and industrial application. FEMS Yeast Research, 14, 813-825. 